\title{
Comparison of Two Different Photorefractors with Skiascopy Measurements in Healthy Children
}

\author{
(1) Gülay Yalçınkaya, (10) Osman Bulut Ocak, (1) ihsan Çakır, (1) Aslı Inal, (10) Birsen Gökyiğit \\ University of Health Sciences Turkey, İstanbul Beyoğlu Eye Research and Training Hospital, Clinic of Ophthalmology, İstanbul, Turkey
}

Cite this article as: Yalçınkaya G, Ocak OB, Çakır İ, İnal A, Gökyiğit B. Comparison of Two Different Photorefractors with Skiascopy Measurements in Healthy Children. J Acad Res Med 2021;11(2):206-10

\begin{abstract}
Objective: Comparing refractive values determined by two photorefractory devices (Plusoptix ${ }^{\circledR}$ A09, GmbH, Nuremberg, Germany and SureSight ${ }^{\circledR}$, Welch Allyn Co, New York, USA) with refractive values obtained by skiascope after cycloplegia with $1 \%$ cyclopentolate hydrochloride in healthy children.

Methods: Cases aged between 48 and 132 months were evaluated for this cross-sectional study. Cases with no ophthalmic pathology in both eyes and uncorrected visual acuity of 1.0 were included in the study. In all cases, refractive measurements were performed first with Plusoptix ${ }^{\circledast}$ and then with SureSight ${ }^{\circledR}$. After providing cycloplegia with $1 \%$ cyclopentolate hydrochloride, skiascopy was performed. The correlation between the measurements obtained was evaluated with the Pearson correlation coefficient, and the compatibility was evaluated with the Bland-Altman analysis. Results: The mean spherical values of 52 subjects measured by cycloplegic skiascopy, Plusoptix ${ }^{\circledR}$ and SureSight ${ }^{\circledR}$ were $0.88 \pm 2.07$ dioptry (D), $0.69 \pm 1.78 \mathrm{D}$ and $1.64 \pm 1.06 \mathrm{D}$, respectively; mean of cylindrical measurements are $-0.73 \pm 0.68 \mathrm{D},-0.92 \pm 0.67 \mathrm{D}$ and $-0.83 \pm 0.70 \mathrm{D}$, respectively. Comparing Plusoptix ${ }^{\circledR}$ with skiascopy, SureSight ${ }^{\circledR}$ with skiascopy, Plusoptix ${ }^{\circledR}$ with SureSight ${ }^{\circledR}$ measurements, a high positive correlation was found between spherical values $(r=0.861, r=0.736, r=0.721$, respectively); a positive correlation was also found between cylindrical values $(r=0.602, r=0.675, r=0.901$, respectively). Skiascopic spherical and cylindrical measurements with Plusoptix ${ }^{\circledR}$, and skiascopic spherical and cylindrical measurements with SureSight ${ }^{\circledR}$ were found to be compatible with each other (within 95\% confidence interval, lower limit: -2.65, upper limit: 1.89; lower limit: -1.35, upper limit: 0.95; lower limit: -3.56, upper limit: 2.06; lower limit: -1.20, upper limit: 0.98). Spherical and cylindrical measurements obtained with Plusoptix ${ }^{\circledR}$ and SureSight ${ }^{\circledR}$ were found to be consistent with each other (within 95\% confidence interval, lower limit: -3.39 , upper limit: 1.49; lower limit: -0.67 , upper limit: 0.51).

Conclusion: It was concluded that the results of these three measurements in childhood were compatible with each other.

Keywords: Photorefractometer, Plusoptix ${ }^{\circledast}$, retinoscopy, cycloplegic skiascopy, SureSight ${ }^{\circledR}$
\end{abstract}

\section{INTRODUCTION}

Ophthalmological examination begins with the detection of the refractive error (1). In the early detection of anisometropia, which is a cause that may lead to vision loss, especially amblyopia, the detection of refractive error is necessary (2-5).

The gold standard for the detection of refractive error is skiascopic measurement after cycloplegia with 1\% atropine sulfate (6-8). It has been shown that skiascopic measurements after $1 \%$ cyclopentolate hydrochloride drop give similar results with measurements after cycloplegia with atropine (9). In recent studies, it has been shown that photorefractors, which are used as scanning programs, are also reliable and effective in detecting refractive errors $(10,11)$.

Our aim in this study is to compare the refractive error measurement values determined by two separate photorefractors (Plusoptix ${ }^{\circledR}$

ORCID IDs of the authors: G.Y. 0000-0001-6248-5902; O.B.O. 0000-0002-8154-6771; I.Ç. 0000-0003-3784-1607; A.I. 0000-0003-1944-5731; B.G. 0000-0002-4154-4106.

Sorumlu Yazar/Corresponding Author: Gülay Yalçınkaya, E-mail:ykgulay@gmail.com
Geliş Tarihi/Received Date: 13.01.2021 Kabul Tarihi/Accepted Date: 25.06.2021

CCopyright 2021 by University of Health Sciences Turkey, Gaziosmanpaşa Training and Research Hospital. Available on-line at www.jarem.org 
A09, GmbH, Nuremberg, Germany and SureSight ${ }^{\circledR}$, Welch Allyn Co, New York, USA) and the refractive error measurement values obtained by skiascopy after cycloplegia with $1 \%$ cyclopentolate hydrochloride in healthy children without amblyopia. There has been no previous study comparing these two devices with each other and with the skiascopic measurement after a drop of $1 \%$ cyclopentolate hydrochloride.

\section{METHODS}

The cases aged between 48 and 132 months, who applied to our hospital's general polyclinic unit for routine control between May 2019 and August 2019, were evaluated for this cross-sectional study. The cases with no ophthalmic pathology in both eyes and a corrected visual acuity of 1.0 with Snellen or E chart were included in the study. The ones with corrected visual acuity of 1.0 in one or both eyes, and with corrected visual acuity of 1.0 in both eyes but with ophthalmic pathology (acute bacterial conjunctivitis, previous keratitis, etc.) and cases with no vision data in Snellen or E chart were excluded from the study.

Approval for our study was obtained from the Ethics Committee of University of Health Sciences Turkey, Istanbul Training and Research Hospital with the decision number 1975 dated 13.09.2019, and our study was carried out in accordance with the terms of the Declaration of Helsinki. Informed written consent was obtained from the parents of each child included in the study.

\section{Plusoptix ${ }^{\circledR}$ A09}

It is a non-invasive, binocular photorefractometer that can be used in children aged 6 months and older, with symbols and sounds that will attract the attention of the child (12). It consists of a portable infrared camera (13). It is aimed to minimize the effect of accommodation by taking measurements from a distance of 1 meter. The measuring range starts from -7.00 dioptry (D) for spherical and cylindrical values and continues by increasing $0.25 \mathrm{D}$ until $+5.00 \mathrm{D}$ (12). There is no need for cycloplegia when measuring (14).

\section{SureSight ${ }^{\circledR}$}

SureSight ${ }^{\circledR}$ is an easily portable, noninvasive, monocular photorefractometer. The measured distance is 35 centimeters (14). The central red light enables the child to fixate while the measurement is taken (15). The measuring range starts from $-5.00 \mathrm{D}$ for spherical and cylindrical values and continues by increasing $0.25 \mathrm{D}$ until $+5.00 \mathrm{D}(14)$. It shows the reliability of the obtained values by grading from 1 to 9 (16). In this study, the measurement was repeated when the confidence value was less than 6. Like Plusoptix ${ }^{\oplus}$, this photorefractometer does not require cycloplegia for measurement (14).

\section{Cycloplegic Skiascopy}

Skiascopy (retinoscopy) is the detection of the refractive error by subtracting $+1.50 \mathrm{D}$ from the measurements made at an arm distance $(67 \mathrm{~cm})$ from the patient through the retinoscope. In order to detect the refractive error of the patient's right eye, the person performing the test holds the retinoscope with his/her right hand and evaluates with his/her right eye. The same situation is opposite for the left eye (17). Heine Beta ${ }^{\circledR} 200$ retinoscope (HEINE Ophthotecnic, Herrsching, Germany) was used for skiascopy in this study.

\section{Refractive Error Measurements}

The refractive error measurements of all cases were first recorded by the technician in the dark room from a distance of $1 \mathrm{~m}$ using Plusoptix ${ }^{\circledast}$. Refractive values were then measured by the clinician from a $35 \mathrm{~cm}$ distance with SureSight ${ }^{\oplus}$ device. The visual acuities of the cases were evaluated by the same clinician using Snellen or E charts, each eye separately, and complete ophthalmological examinations were performed. At the end of the examination, one drop of $1 \%$ cyclopentolate hydrochloride was administered to all patients for cycloplegia 3 times at five-minute intervals. Forty minutes later, skiascopic examination was performed by the other clinician, who was unaware of the refractive values gathered with Plusoptix ${ }^{\circledast}$ and SureSight ${ }^{\oplus}$, and the measurement values were recorded.

\section{Statistical Analysis}

The refractive error measurement values for both eyes were statistically analyzed with the SPSS $20.0^{\circledR}$ for Windows program. In order not to affect the reliability of the study statistically, the right eye of all cases was evaluated. The relationship between the measurements taken from the devices was examined with the Pearson correlation coefficient, and the compatibility with the Bland-Altman analysis.

\section{RESULTS}

Fifty-two right eyes of 52 cases were included in the study. 18 of the cases were female and 34 were male. The mean age was $91.50 \pm 25.96$ (range 53-141) months. The averages of the refractive measurement values are shown in Table 1, and the lower and upper limits are shown in Table 2.

Comparing Plusoptix ${ }^{\circledast}$ with skiascopy, SureSight ${ }^{\circledR}$ with skiascopy and Plusoptix ${ }^{\circledast}$ with SureSight ${ }^{\circledast}$ measurements, a high positive correlation was found between spherical values $(r=0.861$, $r=0.736, r=0.721$, respectively). The cylindrical values obtained with Plusoptix ${ }^{\circledR}$ and SureSight ${ }^{\circledR}$ were highly positively correlated $(r=0.901)$, while Plusoptix ${ }^{\oplus}$ and skiascopy and SureSight ${ }^{\oplus}$ and skiascopy cylindrical measurements were moderately positively correlated ( $r=0.602, r=0.675$, respectively). A high positive correlation was found between spherical equivalents from Plusoptix ${ }^{\circledR}$ and skiascopic measurement $(r=0.863)$. Spherical equivalents obtained from Plusoptix ${ }^{\circledR}$ and SureSight ${ }^{\circledR}$ and SureSight ${ }^{\circledR}$ and skiascopic measurements were moderately positively correlated ( $r=0.683, r=0.685$, respectively). A moderate positive correlation was found between the axis values obtained with Plusoptix ${ }^{\circledast}$ and skiascopy, SureSight ${ }^{\circledR}$ with skiascopy, 
and Plusoptix ${ }^{\circledast}$ with SureSight ${ }^{\circledR}$ devices $(r=0.550, r=0.363, r=0.482$, respectively).

According to the Bland-Altman analysis, it was determined that both photorefractometers were compatible with the skiascopic measurement and with each other (Figures 1,2 and 3). The results of the Bland-Altman analysis, in which the compatibility of spherical measurements obtained from two different photorefractometers with the spherical measurements obtained by skiascope are evaluated, are shown in Figures 1 and 2, and the results of the Bland-Altman analysis in which the compatibility with each other is evaluated are shown in Figure 3. When Plusoptix ${ }^{\oplus}$ and skiascopic cylindrical measurements were evaluated, only 1 case was found outside the confidence interval (within $95 \%$ confidence interval, lower limit: -1.35 , upper limit: 0.95 , mean: -0.20 , standard deviation: 0.58). Considering SureSight ${ }^{\circledR}$ and skiascopic cylindrical measurements, 2 cases were outside the confidence interval (within 95\% confidence interval, lower limit: -1.20, upper limit: 0.98 , mean: -0.11 , standard deviation: 0.55 ). When the cylindrical measurements obtained with Plusoptix ${ }^{\circledast}$ and SureSight ${ }^{\circledast}$ were evaluated, it was observed that 2 subjects were outside the confidence interval (within 95\% confidence interval, lower limit: -0.67 , upper limit: 0.51 , mean: -0.08 , standard deviation: 0.30 ).

\section{DISCUSSION}

Detection of refractive error in the pediatric age group is one of the most important factors in the detection of amblyopia, which can be treated in this age (18). Screening tests to be performed with photorefractometry in the early period for the determination of amblyopia have been used frequently, especially in schoolage children (19-21). Our aim in this study is to evaluate the compatibility of measurements obtained with two separate photorefractometer devices with skiascopic measurements

Table 1. Refractive error measurement values determined by 3 different methods in cases

\begin{tabular}{|c|c|c|c|}
\hline & $\begin{array}{l}\text { Plusoptix } \\
\text { A09 }{ }^{\circledR}\end{array}$ & SureSight ${ }^{\circledR}$ & $\begin{array}{l}\text { Skiascopy after } \\
\text { cycloplegia }\end{array}$ \\
\hline Spherical (D) & $0.69 \pm 1.78$ & $1.64 \pm 1.06$ & $0.88 \pm 2.07$ \\
\hline Cylindrical (D) & $-0.92 \pm 0.67$ & $-0.83 \pm 0.70$ & $-0.73 \pm 0.68$ \\
\hline $\begin{array}{l}\text { Spherical } \\
\text { equivalent (D) }\end{array}$ & $0.23 \pm 1.68$ & $1.23 \pm 0.99$ & $0.52 \pm 2.01$ \\
\hline Axis $\left({ }^{\circ}\right)$ & $69.77 \pm 70.64$ & $76.15 \pm 72.41$ & $91.67 \pm 77.19$ \\
\hline
\end{tabular}

Table 2. Lower and upper limits of refractive error measurements determined by 3 different methods in cases

\begin{tabular}{|l|l|l|l|}
\hline & $\begin{array}{l}\text { Plusoptix } \\
\text { A09 }\end{array}$ & SureSight & \\
\hline Spherical (D) & -5.25 to +4.25 & -1.00 to +4.00 & $\begin{array}{l}\text { Skiascopy after } \\
\text { cycloplegia }\end{array}$ \\
\hline $\begin{array}{l}\text { Cylindrical (D) } \\
\text { Spherical }\end{array}$ & -2.75 to 0 & -3.00 to 0 & -3.00 to +5.00 \\
\hline $\begin{array}{l}\text { equivalent (D) } 0 \\
\text { D: dioptry }\end{array}$ & -5.50 to +3.75 & -1.13 to +3.63 & -4.00 to +5.00 \\
\hline
\end{tabular}

performed after cycloplegia with $1 \%$ cyclopentolate hydrochloride.

The gold standard for the determination of refractive error is skiascopy performed after cycloplegia obtained with $1 \%$ atropine sulfate drop (6-8). In recent studies in the literature, it has been shown that photorefractometers also give results compatible with skiascopy (10-13). Photorefractometers are devices that enable the determination of refractive error as a result of the reflection of the red reflex of the retina through the non-dilated pupil and its detection with infrared cameras and evaluation with various software (22). Photorefractometers are easy to use and provides noncontact, fast and comfortable measurements to be taken $(22,23)$.

The advantages of taking measurements with Plusoptix ${ }^{\circledR}$ are that cycloplegia is not required and the device is portable and easy to

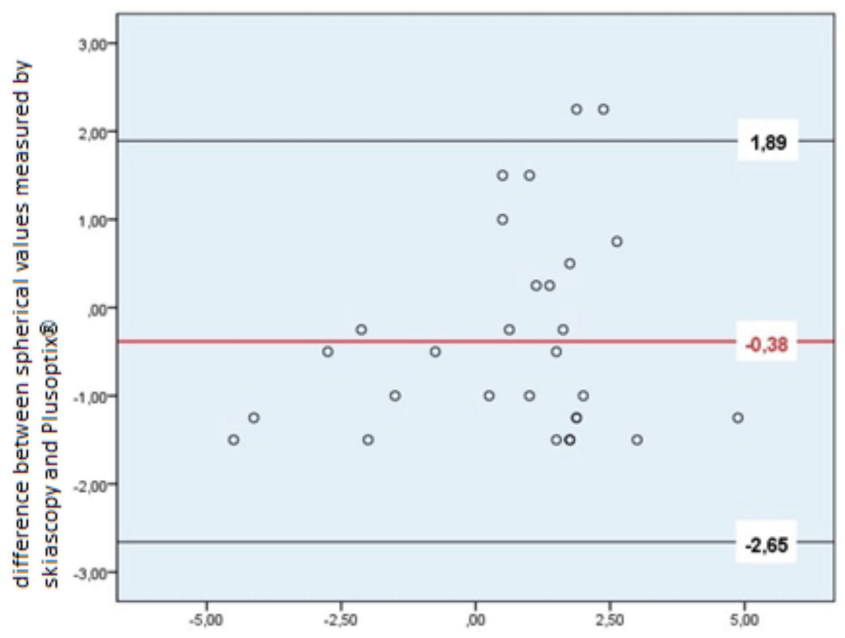

average of spherical values measured by skiascopy and Plusoptix

Figure 1. Bland-Altman compatibility analysis of spherical refractive values in Plusoptix ${ }^{\circledR}$ and skiascopic measurements

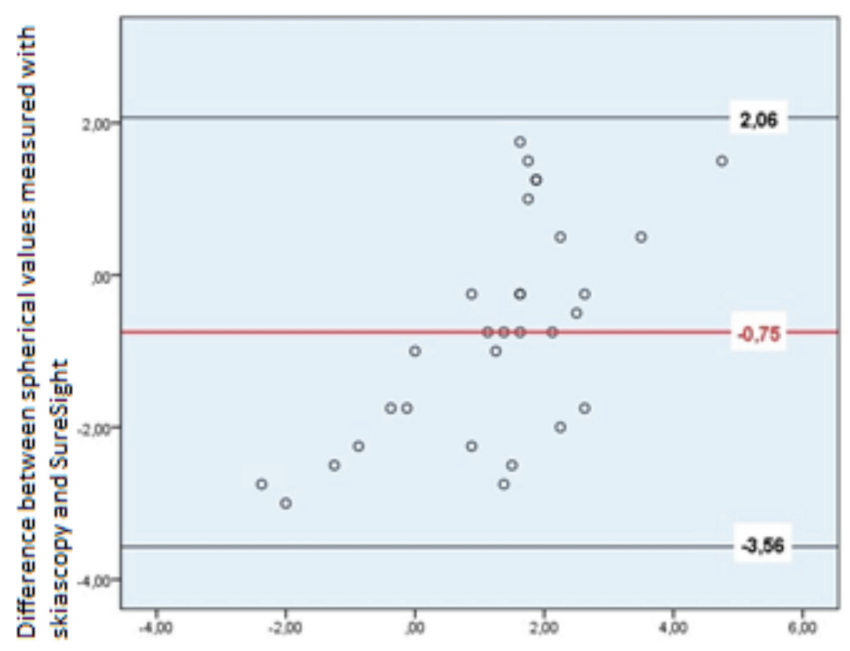

Average of soherical values measured bv skiascoov and SureSizht

Figure 2. Bland-Altman compatibility analysis of spherical refractive values in SureSight ${ }^{\circledR}$ and skiascopic measurements 


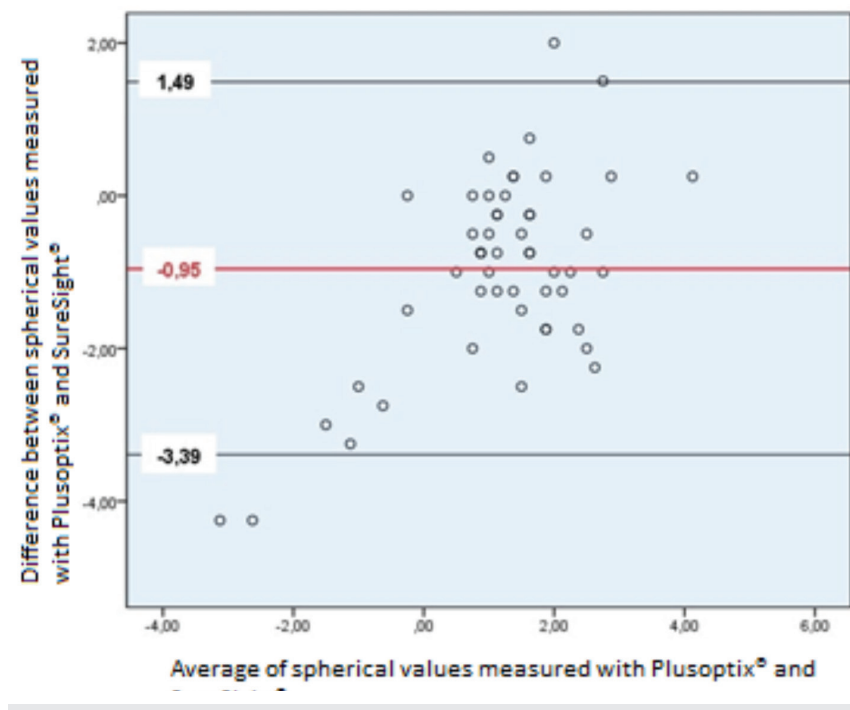

Figure 3. Bland-Altman compatibility analysis of spherical refractive values in Plusoptix ${ }^{\circledR}$ and SureSight ${ }^{\circledR}$ measurements

use. The disadvantage of Plusoptix ${ }^{\circledR}$ is that it cannot numerically detect refractive errors outside the range of $-7.00 \mathrm{D}$ to $+5.00 \mathrm{D}$. In addition, it requires a dark environment for measurement, which makes the examination of the pediatric group more difficult, where it is not easy to cooperate during the examination. YIlmaz et al. (12) compared Retinomax ${ }^{\circledast}$, retinoscopy and Plusoptix ${ }^{\circledast}$ A09 measurements in 200 cases aged 4-12 years, and found no significant difference between spherical and cylindrical values between the three measurement methods, and stated that all three methods could be used in screening. Erdurmus et al. (24) compared Plusoptix ${ }^{\oplus}$ and cycloplegic skiascopy measurements with Pearson correlation analysis in 204 eyes and found positive correlations between spherical, cylindrical and spherical equivalents ( $r=0.63, r=0.70, r=0.63$, respectively). In our study, there was a positive correlation between the refractive values obtained by skiascopy by providing cycloplegia and the values obtained by Plusoptix ${ }^{\circledast}$. Our measurements with cycloplegic skiascopy and Plusopti ${ }^{\circledR}$ were consistent with each other (Figure 1). On the other hand, in a study conducted by Yan et al. (4), Plusoptix ${ }^{\circledR}$ and cycloplegic retinoscopy measurements of 178 cases were compared, and they found a significant difference between spherical values $(p<0.001)$ and found no significant difference between cylindrical values $(p=0.14)$. Based on these results, they stated that Plusoptix ${ }^{\circledast}$ measurements were not compatible with cycloplegic skiascopy and their use in screening was doubtful (4). The fact that there were 86 amblyopian cases in the study, that 63 cases with strabismus were not excluded from the study, and that the corrected visual acuity of the cases were in a wide range from 0.1 to 1.0 may have played a role in the lack of agreement between the two measurement methods.

When evaluating refractive errors with SureSight ${ }^{\oplus}$, the fact that cycloplegia is not required, the device is portable, measurement can be taken in any dark or bright environment provides comfort in clinical practice; however, a distance of $35 \mathrm{~cm}$ is required during the measurement, which can frighten children and make the examination difficult. In a study conducted by Silverstein et al. (25) with 15,749 cases, they stated that SureSight ${ }^{\circledR}$ photorefractometer could be used in screening programs. In a study conducted by Ying et al. (11) with 4,040 preschool children aged 3-5 years, they compared cycloplegia-free retinoscopy, Retinomax $^{\circledast}$ and SureSight ${ }^{\circledR}$ measurements, and found no significant difference in scans between the three measurements, and suggested that any one of them could be used for refractive error screening in the pediatric group. In our study, there was a positive correlation between the refractive values obtained by skiascopy by providing cycloplegia and the values obtained by the SureSight ${ }^{\circledast}$ photorefractometer, and the values obtained by both methods were compatible with each other (Figure 2).

Silbert et al. (14) retrospectively measured the refractive values with SureSight ${ }^{\oplus}$ and Plusoptix ${ }^{\oplus}$ A09 in 90 children aged 1-17 years and found no significant difference between the devices in the refractive values they obtained. Silbert et al. (16) reported that Plusoptix ${ }^{\circledast}$ and SureSight ${ }^{\oplus}$ photorefractometers could be used in screening programs in their study with 216 cases with a mean age of 9 years. We also found that the measurements we made with both photorefractometers were compatible with each other (Figure 3). There is no study in the literature comparing cycloplegic skiascopy, Plusoptix ${ }^{\circledR}$ and SureSight ${ }^{\circledR}$ photorefractometers with each other.

\section{Study Limitations}

Although the age group was appropriate in our study, the number of cases was a limiting factor. Since eyes with uncorrected visual acuity of 1.0 were included, eyes with extreme refractive error were excluded from the study, which is one of the limitations of our study.

\section{CONCLUSION}

As a result, it was seen that the results of these three measurements in childhood were compatible with each other.

Ethics Committee Approval: Approval for our study was obtained from the Ethics Committee of University of Health Sciences Turkey, İstanbul Training and Research Hospital with the decision number 1975 dated 13.09.2019.

Informed Consent: Informed written consent was obtained from the parents of each child included in the study.

Peer-review: Externally peer-reviewed.

Author Contributions: Surgical and Medical Practices - G.Y., O.B.O., I.Ç.; Concept - O.B.O., A.I., B.G.; Design - G.Y., I.Ç.; Data Collection and/or Processing - G.Y., I.Ç.; Analysis and/or Interpretation - G.Y., I.Ç.; Literature Search - G.Y., I.Ç.; Writing - G.Y., O.B.O.

Conflict of Interest: The authors have no conflict of interest to declare.

Financial Disclosure: The authors declared that this study has received no financial support.

\section{REFERENCES}

1. Bennett AG. An historical review of optometric principles and techniques. Ophthalmic Physiol Opt 1986; 6: 3-21. 
2. Gupta M, Rana SK, Mittal SK, Sinha RNP. Profile of amblyopia in school going (5-15 years) children at state level referral hospital in Uttarakhand. J Clin Diagn Res 2016; 10: SC09-11. doi: 10.7860/JCDR/2016/16026.8866.

3. Kurt A, Kılıç R, Polat OA. Refraksiyon kusuru ve şaşılı̆̆ı olan hastalarda ambliyopi sıklığı. MN Ophthalmology 2016; 23: 174-8.

4. Yan XR, Jiao WZ, Li ZW, Xu WW, Li FJ, Wang LH. Performance of the Plusoptix A09 photoscreener in detecting amblyopia risk factors in Chinese children attending an eye clinic. PLoS One 2015; 10: e0126052. doi: 10.1371 /journal.pone. 0126052 .

5. Duman R, Atilla H, Çatak E. Characteristics of anisometropic patients with and without strabismus. Turk J Ophthalmol 2018; 48: 23-6.

6. Su T, Min X, Liu S, Li F, Tan X, Zhong Y, et al. Accuracy of three common optometry methods in examination of refraction in juveniles. Zhong Nan Da Xue Xue Bao Yi Xue Ban 2016; 41: 174-81.

7. Hernandez-Moreno L, Vallelado-Alvarez A, Martin R. Repeatability of ARK-30 in a pediatric population. Indian J Ophthalmol 2018; 66: 1262-7.

8. Schimitzek T, Haase W. Efficiency of a video-autorefractometer used as a screening device for amblyogenic factors. Graefes Arch Clin Exp Ophthalmol. 2002; 240: 710-6

9. Sanchez RN, Choudhury F, Tarczy-Hornoch K, Borchert M, Cotter SA, Azen $\mathrm{S}$, et al. Effect of cyclopentolate versus atropine on cycloplegic refraction: The multi-ethnic pediatric eye disease study. Invest Ophthalmol Vis Sci 2008; 49: 1454.

10. Kinori M, Molina I, Hernandez EO, Robbins SL, Granet DB, Coleman AL, et al. The plusoptix photoscreener and the retinomax autorefractor as community-based screening devices for preschool children. Curr Eye Res 2018; 43: 654-8.

11. Ying G, Maguire M, Quinn G, Kulp MT, Cyert L, Vision In Preschoolers (VIP) Study Group. ROC analysis of the accuracy of non cycloplegic retinoscopy, retinomax autorefractor, and suresight vision screener for preschool vision screening. Invest Ophthalmol Vis Sci 2011; 52: 9658-64.

12. Yılmaz I, Özkaya A, Alkın Z, Özbengi Ş, Yazıcı AT, Demirok A. Comparasion of the plusoptix A09 and retinomax k-plus 3 with retinoscopy in children. J Pediatr Ophthalmol Strabismus 2015; 52: 37-42.

13. Yalcın E, Sultan P, Y,Imaz S, Pallikaris IG. A comparison of refraction defects in childhood measured using plusoptix S09, 2WIN photorefractometer, benchtop autorefractometer, and cycloplegic retinoscopy. Semin Ophthalmol 2017; 32: 422-7.

14. Silbert D, Matta N, Tian J, Singman E. Comparing the suresight autorefractor and the plusoptix photoscreener for pediatric vision screening. Strabismus 2014; 22: 64-7.

15. Vision in Preschoolers (VIP) Study Group. Impact of confidence number on accuracy of the suresight vision screener. Optom Vis Sci 2010; 87: 96103.

16. Silbert DI, Matta NS, Ely AL. Comparison of SureSight autorefractor and plusoptiX A09 photoscreener for vision screening in rural Honduras. J AAPOS 2014; 18: $42-4$

17. Doherty SE, Doyle LA, McCullough SJ, Saunders KJ. Comparison of retinoscopy results with and without $1 \%$ cyclopentolate in school-aged children. Ophthalmic Physiol Opt 2019; 39: 272-81.

18. Mitchell DE, Freeman RD, Millodot M, Haegerstrom G. Meridional amblyopia: evidence for modification of the human visual system by early visual experience. Vision Res 1973; 13: 535-58.

19. Teberik K, Eski MT, Kaya M, Ankaralı H. A comparison of three different photoscreeners in children. J Pediatr Ophthalmol Strabismus 2018; 55: 306-11.

20. Williams T, Morgan LA, High R, Suh WD. Critical assessment of an ocular photoscreener. J Pediatr Ophthalmol Strabismus 2018; 55: 194-9.

21. Peterseim MM, Papa CE, Wilson ME, Davidson JD, Shtessel M, Husain $M$, et al. The effectiveness of the Spot Vision Screener in detecting amblyopia risk factors. J AAPOS 2014; 18: 539-42.

22. Miller JM, Lessin HR. Instrument-based pediatric vision screening policy statement. Pediatrics 2012; 130: 983-6.

23. Kılavuzoğlu AEB, Coşar CB, Üçbaşaran E. Plusoptix CR03 fotorefraktometre cihazı ile rutin göz muayenesi yapılan bir yaşındaki bebeklerin refraksiyon değerleri. MN Ophthalmology 2014; 21: 52-5.

24. Erdurmus M, Yagci R, Karadag R, Durmus M. A comparison of photorefraction and retinoscopy in children. J AAPOS 2007;11: 606-11.

25. Silverstein E, Lorenz S, Emmons K, Donahue SP. Limits on improving the positive predictive value of the Welch Allyn SureSight for preschool vision screening. J AAPOS 2009; 13: 45-50. 